\title{
Study of Knowledge of Breastfeeding Practices in Infants from 0 to 6 Months
}

\author{
Y. P. Adepo ${ }^{1}$, S. Soro ${ }^{1}$, B. J. J. Touzou ${ }^{1}$, K. O. Chatigre ${ }^{1}$, G. H. Biego ${ }^{1}$, K. E. Koffi ${ }^{1} \&$ C. S. Kati ${ }^{2}$ \\ ${ }^{1}$ Laboratory of Biochemistry and Food Science, Faculty of Biosciences University Félix Houphouet-Boigny, 22 \\ BP 582 Abidjan 22, Côte d'Ivoire \\ ${ }^{2}$ Laboratory of Nutrition and Pharmacology, Faculty of Biosciences University Félix Houphouet-Boigny, 22 BP \\ 582 Abidjan22, Côte d'Ivoire
}

Correspondence: Y. P. Adepo, Laboratory of Biochemistry and Food Science, Faculty of Biosciences University Félix Houphouet-Boigny, 22 BP 582 Abidjan 22, Côte d'Ivoire. E-mail: adepoyapo1@ gmail.com

Received: April 26, 2021

Accepted: December 29, $2021 \quad$ Online Published: January 9, 2022

doi:10.5539/jfr.v11n1p23

URL: https://doi.org/10.5539/jfr.v11n1p23

\begin{abstract}
The rate of exclusive breastfeeding from 0 to 6 months in Côte d'Ivoire was $16.67 \%$ in 2014. The objective of this study is to identify the difficulties related to the practice of exclusive breastfeeding of infants from birth to 6 months with a view to finding sustainable solutions for its implementation. A survey study was carried out on a sample of 200 women in the municipality of Bingerville from 7 October 2020 to 7 February 2021. After analysis, the results of the survey show that in the Bingerville locality of Côte d'Ivoire, the difficulties relating to the decline in exclusive breastfeeding are largely linked to the insufficient production of breast milk. The results have made it possible to record some species of food plants. They undoubtedly possess lactogenic properties, which make it possible to cope with the insufficient production of milk in the udder. Thus, after 24 hours, these food plants have made it possible to increase the production of breast milk in the udders intended for infants. The registered food plants will help to ensure the food security of the infant through the improvement of milk production in breastfeeding mothers.
\end{abstract}

Keywords: breastfeeding mother, exclusive breastfeeding, food plants

\section{Introduction}

Exclusive breastfeeding is the act of feeding the newborn only breast milk without the addition of water, decoction, fruit juice, milk, herbal tea or other foods except prescribed medication (Kramer \& Kakuma, 2004). The health benefits of colostrum as a primary breast milk source for young children are widely recognized around the world.

Colostrum has a yellowish colour and is very rich in antibodies, which are essential for the development of the infant's immunity and the effective fight against infections and diseases (Tchenar, 2017).

Breast milk combines the qualities of the lowest cost price, the highest quality and the most attractive presentation (Mama, 2012). Breastfeeding has advantages in terms of family income and a nation's economy. WHO concludes that widespread breastfeeding could prevent the deaths of 823,000 children under the age of five worldwide each year, as well as preventing several childhood diseases. This practice would also reduce the annual number of deaths from breast cancer by 20,000 (Tchenar, 2017).

UNICEF estimated in 2010 that the lives of 1.2 million children worldwide could be saved each year if the practice were widespread. However, in West and Central Africa, only $20 \%$ of young children under 6 months of age are exclusively breastfed (Sokol, Aguayo \& Clark, 2007).

In Côte d'Ivoire, according to a study carried out, the exclusive breastfeeding rate generally shows a progressive decrease from $46.67 \%$ at 1 month to $16.67 \%$ at 6 months (Coulibaly, Ake, Bénié, Traoré \& Dagnan, 2014). Solutions to the difficulties associated with the practice of exclusive breastfeeding are certainly found by some authors (Adepo, 2013). Nevertheless, these solutions remain insufficient and are not adapted to the contexts of each region. It would therefore be imperative to find sustainable solutions. It is in this context that we felt it necessary to initiate this work, the aim of which is to identify the difficulties mentioned in this survey and, above all, to highlight the extent of the difficulties linked to the insufficient production of maternal milk and thus to 
propose solutions using natural means such as plants.

Specifically, it is a question of characterising the socio-demographic state of the survey, of knowing the level of the existence of the insufficient increase in milk production in the udder and of listing the various difficulties of this insufficiency and providing solutions relating to the difficulties linked to the practice of exclusive breastfeeding.

\section{Material and Methods}

\subsection{Study Framework}

Bingerville is a town located in the south of Ivory Coast, on the banks of the Ebrié lagoon. It belongs to the Autonomous District of Abidjan. The city is part of the Abidjan agglomeration.

The demography is estimated at 91,319 inhabitants, the languages spoken are French and Ebrié. It covers an area of $2119 \mathrm{Km}^{2}$. Its geographical position is 5021.3486 north latitude and $3053.1222^{\prime}$ west longitude. It is surrounded by cities such as Alépé, Abidjan, Anyama and Grand-Bassam. The religions practiced are Christian and Muslim. The city is characterised by forest vegetation like most of the southern regions of Ivory Coast. The flora is varied and contains endangered species due to habitat development. The main agricultural activities are:

Oil palm cultivation, cassava cultivation and rubber tree cultivation.

\subsection{Methods}

\subsubsection{Survey}

The target population consisted of rural women in the municipality of Bingerville in a low-income neighborhood. Our data collection tool is a questionnaire that takes into account the locality, the marital situation and the mother's level of education.

It is a descriptive and analytical cross-sectional study. It took place from October 2020 to February 2021. The questionnaires focused on the difficulties of the practice of exclusive breastfeeding and on the day, the infant was put to the breast for the first time. The sampling was based on Lutter (2000) theoretical model of the year 2000 .

\subsubsection{Statistical Analysis}

The survey forms were processed using the Excel spreadsheet. The quantitative data collected was subjected to a descriptive analysis. The experiments carried out made it possible to collect quantitative data. A test of NEWMAN- KEULS with a classification criterion at the $5 \%$ threshold was carried out to evaluate the significant difference in the averages. The test was carried out using the Statisticat software version 7.1.

\section{Results and Discussion}

The results of our survey (Table 1) indicate that most of the mothers were educated $(82.4 \%)$. This predominance of educated women in our study could be explained by the fact that the study took place in a locality close to the city of Abidjan where the schooling rate for young girls is high overall (National Institut of Statistique, 2007). Zengbe-Acray et al. (2012) also found this predominance of educated women in 2012 (70.2\%).

The proportion of women in couples $(90.10 \%)$ is relatively higher than that of women not in couples $(9.90 \%)$. This result is in line with that of Zengbe-Acray et al. (2012) (73.7\%). Our results are also in line with the results of a study conducted in 2010 by Mariko (2010) in Mali on the practice of exclusive breastfeeding, which estimated the proportion of women living in couples at $90.3 \%$.

The interviewers were confronted with several difficulties including fatigue, daily occupation, insufficient production of breast milk, and cases of mother and infant illness. These difficulties led the women to want to abandon exclusive breastfeeding and to subject their infants to non-exclusive breastfeeding, which could consist of mixed or artificial breastfeeding, which could thus cause inconveniences for the infants' health.

The difficulties linked to the practice of exclusive breastfeeding according to the results of our survey are fatigue, illness of the infant and that of the mother, insufficient production of breast milk and the daily occupation of the breastfeeding mother. Thus, the relative difficulty of the mother's daily occupation revealed that most of the mothers were working in the informal sector or were homemakers, given the status linked to the neighborhood in which our study was conducted. This finding is said to be linked to the under-qualification of women, in relation to their low level of education. Indeed, although they were educated, only $10.5 \%$ of the respondents had a higher level of education (Zengbe-Acray et al., 2012).

According to the results of this survey, mothers in low-income neighborhoods do not breastfeed up to six 
months because of their low level of education, as they are very busy with daily chores in order to ensure their daily life. If the daily activities carried out are far away from home, this will affect the good practice of breastfeeding because they will not have the time to breastfeed their infants continuously.

In rural areas, women are overburdened by strenuous activities (fieldwork) for family development, leading them to abandon exclusive breastfeeding early because of lack of availability and support for infant feeding (Kamudoni, Maleta, Shi, de Paoli \& Holmboe-Ottesen, 2010). In both rich and poor countries, the main reasons given by mothers for introducing water or other solid or liquid foods other than breast milk are insufficient milk production (Sibeko, Dhansay, Charlton, Johns \& Gray-Donald, 2005). These difficulties have also been identified by several studies in Africa and around the world. If the mother and/or child is ill, this may also prevent the child from being breastfed properly, which will lead to a decrease in the number of feedings resulting in a decrease in prolactin stimulation, which, in turn, may decrease milk production in the udder. All this may cause the mother to abandon exclusive breastfeeding of the baby in favour of artificial or mixed milk. Maternal and infant illnesses are also an important reason for choosing complementary foods. Indeed, if either the infant or the mother is ill, if remedies have not been found, this illness could contaminate either of them and aggravate the situation, which would constitute a reason for refusing to breastfeed at the child's level. This is the case with diseases such as colds, flu and cholera. The phenomenon of cases of illness that would decrease the number of feedings.

Of all the women surveyed, $53 \%$ of the women in sum subjected their infants to exclusive breastfeeding. In fact, the main difficulty recorded $(40.84 \%)$ according to the results of our survey was the insufficient production of breast milk among breastfeeding mothers. These results are in line with those of Zengbe-Acray et al. (2012) who noted that insufficient milk production was one of the major difficulties encountered by breastfeeding women. However, among those with fatigue (13.36 \%), the mother's daily occupation (5.63\%), the mother's illness $(14.78 \%)$ and that of the infant $(3.5 \%)$ as difficulties combined with insufficient milk production $(40.84 \%)$, among a proportion of $82.43 \%$ having used food plants as lactogenic plants, $53 \%$ of these women overcame the fatigue by using food plants. The registered plants are composed of Euphorbia hirta, Moringa oleifera, Manhiot esculenta, Cyperus esculenta, Zea mays, Arachis hypogaea, cocos nucifera, Pennisetum glaucum and Oryza glaberrina. This suggests that the plants used can cope not only with insufficient milk production but also provide nutrients to combat fatigue. For according to a study conducted by the WHO in 1989, 2010 and 2011, fatigue is a factor limiting milk production in breastfeeding women. In fact, this use of food plants proves to be important because it has enabled a proportion of $53 \%$ of women to improve their milk after 24 hours. This rate of $53 \%$ is also justified by the use of recipes linked to the combination of plants $(80.30 \%)$ which make it easier to improve milk production. However, $47 \%$ of the women who did not subject their infants to exclusive breastfeeding could be explained by the difficult resolution of obstacles to exclusive breastfeeding. In addition to the women who have no knowledge of food plants that can facilitate milk production $(16.56 \%)$, there are the unresolved cases of difficulties that could be the responsibility of women who did not require periods of breastfeeding linked to daily occupations that forced them to move away from the place of residence to carry out the tasks. To this can be added women who certainly have not found adequate remedies for fatigue and those who have not visited health centers in relation to cases of mother and/or child illnesses. These reasons would have led to the abandonment of exclusive breastfeeding. This $47 \%$ rate could also be justified by the use of recipes based on a single plant. In fact, the results showed that the use of the plants allowed, after 24 hours, a significant improvement in milk production in addition to the daily food they consumed.

These same food plants could also deal with difficulties related to atrophy of the udder, nipple and the end of the nipple not very protruding. Indeed, the last two difficulties mentioned would cause insufficient milk production, which was the major difficulty. This capacity of food plants to solve the problem of insufficient milk production could be an effective means of fighting against cancer because of its great capacity to improve milk production, which is a means of fighting against ovarian and breast cancer (Tchenar, 2017). According to the author Michel (1998) breastfeeding allows infants to be protected from infections and diseases, but breastfeeding is also an effective means of significantly reducing the risk of breast and ovarian cancer in breastfeeding mothers, hence the need for it to be used to promote mother-child health. In the surveys, concerning the period when the infant was first fed, $53.40 \%$ of women subjected their infants between the first hour after delivery and the third day. This first feed is mostly made up of the primitive milk called colostrum. It is rich in antibodies and will protect the infant from infections and diseases. Colostrum is a primary milk secreted during the first 3 to 5 days of lactation (Michel, 1998).

The results for the period from the first hour to three days of breastfeeding after delivery is $53.40 \%$. This indicates that more than half of the infants were able to take advantage of the colostrum, which had limited flow after three days after delivery. Fatigue, the mother's daily occupation, cases of maternal and infant illness will cause a 
reduction in the number of feedings; this reduction will result in the inhibition of milk production in the nursing mother's udder.

Table 1. Characteristics of the practice of exclusive breastfeeding with the frequencies of emergence

\begin{tabular}{ll}
\hline Characteristics & population \% \\
\hline Marital status & \\
As a couple & $90.10 \%$ \\
Level of education & \\
School-based & $82.40 \%$ \\
Exclusive breastfeeding & $53 \%$ \\
Difficulties of exclusive breastfeeding practice & \\
Sick mother & $14.78 \%$ \\
Sick Infant & $3.5 \%$ \\
Fatigue & $13.36 \%$ \\
Daily occupation & $5.63 \%$ \\
Insufficient milk production & $40.84 \%$ \\
First breastfeeding & \\
1 hour-3 days & $53.40 \%$ \\
Use of food plants as lactogenic remedies & $82.43 \%$ \\
Women with no knowledge of lactogenic plants & $16.56 \%$ \\
Beyond two plants & $80.30 \%$ \\
Improvement of milk production & \\
24 hours & $50.30 \%$ \\
\hline
\end{tabular}

\section{Conclusion}

The survey showed that the main difficulty in implementing exclusive breastfeeding of infants from 0 to 6 months of age is the insufficient production of breast milk: herbal remedies were effective means of solving this difficulty.

Herbal recipes deserve to be better studied and recognised for their effective use. In addition, it should be noted that difficulties such as cases of illnesses of the breastfeeding mother and/or the infant, the daily occupation of the mother and fatigue have also been recorded. Respective solutions such as encouraging the woman to go to the Health Centers in case of illness and/or of the infant, encouraging the woman to make time available to breastfeed the infant properly. All the solutions considered could be a considerable contribution towards ensuring the infant's food security.

\section{References}

Adepo, Y. P. (2013). Evaluation of the lactogenicity of two plants Euphorbia hirta and Secamone afzelii from Southern Ivory Coast on rats. Biochemistry and Food Sciences. Single PhD thesis. Abidjan, University Félix Houphouët Boigny. pp. 147.

Coulibaly, A., Ake, T. O., Bénié Bi Vroh, J., Traoré, Y., \& Dagnan, N. (2014). Facteurs socioprofessionnels et pratique de l'allaitement exclusif par les primipares à Abidjan (Côte d'Ivoire). Santé Publique, 26(4), 555-562. https://doi.org/10.3917/spub.144.0555

Kamudoni, P. R., Maleta, K., Shi, Z., de Paoli, M. M., \& Holmboe-Ottesen, G. (2010). Breastfeeding perceptions in communities in Mangochi district in Malawi. Acta Paediatrica, 99(3), 367-372.

https://doi.org/10.1111/j.1651-2227.2009.01603.x

Kramer, M. S., \& Kakuma, R. (2004). The optimal duration of exclusive breastfeeding: a systematic review. $A d v$ Exp Med Biol., 554, 63-77. https://doi.org/10.1007/978-1-4757-4242-8_7

Lutter, C. K. (2000). Breastfeeding promotion: is its effectiveness supported by scientific evidence and global changes in breastfeeding behaviors? Advanced Experience Medicine Biology, 478, 355-368.

https://doi.org/10.1007/0-306-46830-1_30

Mama, M. S. (2012). Study of the feeding practices of children aged between 0-6 months from disadvantaged backgrounds in the urban commune of Tessaoua, Maradi region in NIGER. Dissertation presented to the Faculty of Graduate and Postdoctoral Studies of Laval University as part of the Master's in Nutrition program for the degree of Master of Science (M.Sc.). Department of Food and Nutrition Sciences Faculty of Agricultural and Food 
Sciences. Université Laval Québec. pp. 166.

Mariko, O. (2010). Study on women's knowledge, attitudes and practices on exclusive breastfeeding in the district of Sogonikro in commune VI of the district of Bamako. Thesis med. Mali: University of Bamako.

Michel, M. (1998). Breastfeeding and cow's milk. Asculape, 10, 2.

National Institut of Statistique. (2007). Multiple Indicator Cluster Survey, Côte d'Ivoire 2006. Final Report, Abidjan, Côte d'Ivoire: National Institute of Statistics.

Sibeko, L., Dhansay, M. A., Charlton, K. E., Johns, T., \& Gray-Donald, K. (2005). Beliefs, attitudes, and practices of breastfeeding mothers from a periurban community in South Africa. Journal of Human Lactation, 21(1), 31-38. https://doi.org/10.1177/0890334404272388

Sokol, E., Aguayo, V. M., \& Clark, D. (2007). Protecting Breastfeeding in West and Central Africa. 25 years of implementation of the International Code of Marketing of Breast-milk Substitutes.

https://doi.org/10.1177/156482650802900301

Tchenar, S. H. (2017). Exclusive breastfeeding at 6 months Doctoral thesis in Medicine. University ABOU BEKR BELKAID TLEMCEN. Faculty of Medicine Cairo Algeria. pp. 47.

Zengbe-Acray, P., Zengbe-Acray, P., Kouassi, D. P., Sable, P. S., Ahoussou, E. M., ... Tiembre I. (2012). Causes of abandonment of exclusive breastfeeding by mothers. Cah. Santé Publique, 11(2), 7-13.

\section{Copyrights}

Copyright for this article is retained by the author(s), with first publication rights granted to the journal.

This is an open-access article distributed under the terms and conditions of the Creative Commons Attribution license (http://creativecommons.org/licenses/by/4.0/). 